\title{
GENETIC ANALYSES OF THE NF1 GENE IN TURKISH NEUROFIBROMATOSIS TYPE I PATIENTS AND DEFINITION OF THREE NOVEL VARIANTS
}

\author{
Ulusal SD ${ }^{1, *}$, Gürkan $\mathrm{H}^{1}$, Atlı E E $^{1}$ Özal SA ${ }^{2}$, Çiftdemir M ${ }^{3}$, \\ Tozkır H $\mathrm{H}^{1}$, Karal Y Y , Güçlü H², Eker D ${ }^{1}$, Görker I
}

*Corresponding Author: Dr. Selma D. Ulusal, Department of Medical Genetics, Trakya University Faculty of Medicine, D100, Edirne, Turkey. Tel: +90-284-235-7642/2330. Fax: +90-284-235-7652. E-mail: selmaulusal@trakya.edu.tr

\begin{abstract}
Neurofibromatosis Type I (NF1) is a multi systemic autosomal dominant neurocutaneous disorder predisposing patients to have benign and/or malignant lesions predominantly of the skin, nervous system and bone. Loss of function mutations or deletions of the NF1 gene is responsible for NF1 disease. Involvement of various pathogenic variants, the size of the gene and presence of pseudogenes makes it difficult to analyze. We aimed to report the results of 2 years of multiplex ligation-dependent probe amplification (MLPA) and next generation sequencing (NGS) for genetic diagnosis of NF1 applied at our genetic diagnosis center. The MLPA, semiconductor sequencing and Sanger sequencing were performed in genomic DNA samples from 24 unrelated patients and their affected family members referred to our center suspected of having NF1. In total, three novel and 12 known pathogenic variants and a whole gene deletion were determined. We suggest that next generation sequencing is a practical tool for genetic analysis of NF1. Deletion/duplication analysis with MLPA may also be helpful for patients clinically diagnosed to carry NF1 but do not have a detectable mutation in NGS.

Keywords: Genetic diagnosis; Neurofibromatosis type I (NF1); Next generation sequencing (NGS); multiplex ligation-dependent probe amplification (MLPA).
\end{abstract}

\footnotetext{
$\overline{{ }^{1} \text { Department of Medical Genetics, Trakya University Faculty of }}$ Medicine, Edirne, Turkey

2 Department of Opthalmology, Trakya University Faculty of Medicine, Edirne, Turkey

${ }^{3}$ Department of Orthopedics and Traumatology, Trakya University Faculty of Medicine, Edirne, Turkey

${ }^{4}$ Department of Pediatric Neurology, Trakya University Faculty of Medicine, Edirne, Turkey

${ }^{5}$ Department of Child and Adolescent Psychiatry, Trakya University Faculty of Medicine, Edirne, Turkey
}

\section{INTRODUCTION}

Neurofibromatosis Type I (NF1; MIM \#162200), first described by von Recklinghausen in 1882 , is a multi systemic autosomal dominant neurocutaneous disorder predisposing patients to have benign and/or malignant lesions predominantly of the skin, nervous system and bone. It affects about $1 / 3000$ of the population as being one of the most common autosomal dominant disorders [1-3]. Common clinical manifestations include hyperpigmentation lesions of the skin called café-au-lait macules or spots (CAM, CAS), dermal or plexiform neurofibromas, axillary and inguinal freckling, iris hamartomas in the eye called Lisch nodules, optic pathway gliomas, sphenoid or long bone dysplasia and pseudoarthrosis. Some clinical manifestations are age dependent [1,4-7]. Current clinical diagnosis of NF1 is based on the criteria approved by the National Institutes of Health (NIH), Bethesda, MD, USA, consensus in 1988 [8].

Loss of function mutations or deletions of the NF1 (Neurofibromin 1; MIM \#613113) gene located at 17q11.2 encoding a ras-GTPase-activating protein called neurofibromin is responsible for NF1 disease [1]. More than 2000 pathogenic variations listed in the Human Gene Mutation Database (HGMD) including splice site changes, nonsense and missense mutations, deletions, insertions, frameshifts and complex rearrangements [9]. About half of the pathogenic variations found in patients are de novo occurrences. Involvement of various pathogenic variants without a clear hotspot, the large size of the gene and presence of pseudogenes makes it difficult to analyze. Genetic diagnosis generally requires a multi methodological approach [1]. With the advances in next generation sequencing (NGS), it became easier to analyze the whole coding exons of large genes simultaneously in a short time. On the other hand, multiplex ligation-dependent probe 
amplification (MLPA) is a practical way of defining gene deletions and duplications. These techniques together have a powerful tool for genetic diagnosis of NF1 [3,10,11].

Determining the pathogenic variant can assist in diagnosing the patients who have an uncertain diagnosis of NF1 [12,13]. Advances in preimplantation genetic diagnosis (PGD) and prenatal genetic testing might be helpful for the individuals who have a pathogenic variant causing NF1 [14]. In this study, we aimed to present the NF1 gene alterations determined in genomic DNA samples of Turkish NF1 patients using both NGS and MLPA between March 2014 and March 2016.

\section{MATERIALS AND METHODS}

Patients. Genetic screening results for the NF1 gene of 24 patients including 14 males (mean age $9.64 \pm 10.24$ ) and 10 females (mean age $16.30 \pm 15.61$ ) living in the Trakya region of Turkey, who were referred to our department because they were suspected of having NF1 were included in this study.

Whole Blood Collection and DNA Isolation. Peripheral blood samples were obtained from patients after they signed an informed consent forms for genetic investigation. DNA was isolated from blood samples collected in EDTA vacutainers, by BioRobot EZ1 system from Qiagen GmbH (Hilden, Germany) following the manufacturer's instructions. DNA quality (OD260/OD280 1.8-2.0) and concentration analysis were determined both with Nano Drop (Thermo Scientific NanoDrop Products, Wilmington, DE, USA) and Qubit 2.0 fluorometer (Invitrogen, Life Technologies, Eugene, OR, USA) prior to downstream applications.

Multiplex Ligation-Dependent Probe Amplification. The MLPA analysis was performed according to the manufacturer's instructions (MRC-Holland, Amsterdam, The Netherlands), using P081.B2 and P082, B2 probe mixes. The MLPA products were identified and quantified by capillary electrophoresis using ABI PRISM ${ }^{\circledR} 3130 x l$ (Applied Biosystems $^{\circledR}$, Invitrogen Life Technologies, Carlsbad, CA, USA). Gene Mapper(Applied Biosystems, Foster City, CA, USA) and Coffalyser software (MRCHolland) were used for the MLPA analysis.

Next Generation Sequencing. Amino acid coding regions of the NF1 gene (NM_000267) were amplified using primers designed with the Ion AmpliSeq Designer (Life Technologies). Libraries were amplified with the mix including $4 \mu \mathrm{L}$ of $5 \mathrm{X}$ Ion AmpliSeqTM HiFi mix, $10 \mu \mathrm{L}$ of $2 \mathrm{X}$ Ion AmpliSeq TM primer pool, $10 \mathrm{ng}$ of gDNA per reaction and $4 \mu \mathrm{L}$ of nuclease-free water. Thermal cycling conditions were $99^{\circ} \mathrm{C}$ for $2 \mathrm{~min}$., $99^{\circ} \mathrm{C}$ for 15 seconds, 60 ${ }^{\circ} \mathrm{C}$ for 4 min. ( 19 cycles), with a final hold at $10^{\circ} \mathrm{C}$. Following partial digestion of primer sequences, adapters, and barcodes (Ion Xpress, Thermo Fisher Scientific, Waltham, MA, USA) Life Technologies) ligated to the amplicons as described in Ion AmpliSeqTM library preparation manual. Barcoded libraries were equalized using Ion Library Equalizer Kit (Thermo Fisher Scientific). Enriched, templatepositive ion sphere particles (ISPs) were prepared on an Ion One Touch TM 2 System and the Ion One Touch TM ES Instrument (Thermo Fisher Scientific) using the 200 bp chemistry following the manufacturer's manual. Sequencing of enriched particles was performed on the PGM (Thermo Fisher Scientific) with 314 chips according to the user guide for the on Ion PGM sequencing 200 kit version 2 (Thermo Fisher Scientific). Raw data were processed and aligned to hg19 human reference genome (Genome Reference Consortium GRCh37) using the Torrent Suite Software version 5 (Thermo Fisher Scientific).

A coverage analysis plugin was used for each sample to define total reads at the target bases. A minimum 100X coverage for all bases in the targeted region was accepted for a reliable variant calling. Ion Reporter version 4.0 software was used to annotating variants. Integrated Genomics Viewer (IGV) (http://software.broadinstitute.org/software/ igv/) [15] was used to visual assessment of aligned amplicons. The Human Genome Variation Society (HGVS) (http://www.hgvs.org/mutnomen) recommendations were followed for naming novel variants and checked on the Mutalyzer tool (https://mutalyzer.nl/about) [16].

Sanger Sequencing. Sanger sequencing with inhouse designed primer sets was used for segregation analysis and confirmation of the novel pathogenic variants found in NGS. Polymerase chain reaction (PCR) was performed with intronic primers for indicated exons of the NF1 gene. Sequencing reaction was performed with BigDye Terminator 3.1 Kit (PE AppliedBiosystems, Foster City, CA, USA). Dideoxy-terminated products were analyzed on the ABI-PRISM ${ }^{\circledR} 3130$ Genetic Analyzer (PE Applied Bio-systems), according to the manufacturer's instructions.

Classification of Novel Variants. The Human Gene Mutation Database (HGMD) [9], LOVD (Leiden Open Variation Database) [12] and ClinVar databases were used to search the known disease causing NF1 variants. Mutation Taster and Exac Database (http://exac.broadinstitute. org) were considered for all novel variants. The final decision about the classification of variants was given according to American College of Medical Genetics and Genomics and the Association for Molecular Pathology (ACMG) 2015 Guidelines [17]. 


\section{RESULTS}

Pathogenic Variant Distribution. In total, a large gene deletion (patient \#17) and 15 different pathogenic variants were determined. Truncating pathogenic variants either due to small deletions (3/18) or point mutations (4/18) had the highest frequency followed by splice site mutations (6/18). Missense mutations (2/18), in-frame deletion (1/18) and a large gene deletion (1/18) were also defined in the studied population with relatively rare frequencies (Table 1).

Three of the pathogenic variants were novel (patients $\# 6$, \#8, \#12). One of the novel pathogenic variations, c.3230_3230delT, predicted to cause p.(Ser1078Hisfs*3), was colocated with a previous pathogenic variation reported in LOVD (patient data \#0060922). This previous pathogenic variation was a duplication of Timin, whereas in our patient it was a deletion of the first Timin base of codon 1078 (NM_000267). The second novel pathogenic variant, c.4802delT, p.(Leu1601Cysfs*2) in the clinically affected father of the index patient. Absence of this variant in the unaffected family members and in the Exac database supported the pathogenic features of this frameshift variant. A broken tibia because of a severe pseudoarthrosis (Figure 1) was determined in this patient who had inherited this novel pathogenic variation from his father who had cafeau-lait spots and neurofibromas all over his body but he had no tibial pseudoarthrosis in his medical history. Another novel variation was c.5630 $\mathrm{T}>\mathrm{A}$, predicted to cause a truncated protein [p.(Leu 1877*)]. This novel pathogenic variation was inherited from the father who have cafe-aulait macules.

Distribution of pathogenic variants across the domains is shown in Figure 2. Forty percent of pathogenic variants were in the $\mathrm{C}$-terminal region (Figure 2), whereas none of the pathogenic variants found were localized inside the coding region of tubulin binding domain.

We did not define any pathogenic variation or deletion in seven out of 24 index patients who were referred to our center suspected of having NF1. Five out of seven of these mutation-negative patients did not meet the NIH diagnostic

Table1. Mutations found in the patients and their clinical features.

\begin{tabular}{|c|c|c|c|c|c|c|}
\hline \# & Sex-Age & \begin{tabular}{|l|} 
NIH \\
Criteria \\
\end{tabular} & Additional Findings & Pathogenic Variant (NM_000267) & \begin{tabular}{|l|} 
Genetic \\
Analysis \\
\end{tabular} & Ref. \\
\hline$\# 1$ & M-3 & $\mathrm{a} ; \mathrm{f}$ & none & c.311T>G; p.(Leu104Ter) & NA & {$[18]$} \\
\hline$\# 2$ & F-13 & $\mathrm{a}$ & learning disability & c.731-1G $>C$ & NA & {$[19]$} \\
\hline \#3 & M-7 & $\mathrm{a} ; \mathrm{b} ; \mathrm{e} ; \mathrm{g}$ & none & c.1541_1542delAG; p.(Gln514Argfs) & NA & {$[20]$} \\
\hline$\# 4$ & M-1 & $\mathrm{a}$ & none & c.2693C > T; p.Leu898Pro & NA & {$[21]$} \\
\hline$\# 5$ & M-7 & $\mathrm{a} ; \mathrm{b} ; \mathrm{g}$ & none & c. $3113+1 \mathrm{G}>\mathrm{C}$ & NA & {$[12]$} \\
\hline \#6 & F-8 & $\mathrm{a} ; \mathrm{c} ; \mathrm{g}$ & $\begin{array}{l}\text { T2 flair hyperintense signals } \\
\text { in left globus palliadus level }\end{array}$ & c.3230_3230delT; p.(Ser1078Hisfs*3) & NA & $\begin{array}{l}\text { This } \\
\text { report }\end{array}$ \\
\hline$\# 7$ & F-52 & $a ; b ; d$ & none & c. $3709-2 \mathrm{~A}>\mathrm{G}$ & NA & {$[22]$} \\
\hline \#8 & F-7 mths & $a ; b ; f ; g$ & none & c.4082delT; p.Leu1601Cysfs*2) & $\begin{array}{l}\text { paternally } \\
\text { inherited }\end{array}$ & {$[12]$} \\
\hline$\# 9$ & M-41 & $\mathrm{a} ; \mathrm{b}$ & none & c.4867G $>$ C; p.(Asp1623His) & NA & {$[12]$} \\
\hline$\# 10$ & M-7 & $\mathrm{a} ; \mathrm{d}$ & $\begin{array}{l}\text { surgery due to severe } \\
\text { bowel obstruction; T2 flair } \\
\text { hyper-intense signals in both } \\
\text { cerebellar hemispheres }\end{array}$ & c.5389C $>$ T; p.(Arg1947Ter) & NA & {$[23]$} \\
\hline \#11 & F-17 & $\mathrm{a} ; \mathrm{e}$ & $\begin{array}{l}\text { coroidal coloboma } \\
\text { on the left eye }\end{array}$ & c. $5546+5 \mathrm{G}>\mathrm{A}$ & NA & {$[18]$} \\
\hline$\# 12$ & $\mathrm{~F}-2$ & $\mathrm{a}$ & convulsion & c.5630T>A; p.(Leu1877*) & \begin{tabular}{|l|} 
paternally \\
inherited
\end{tabular} & $\begin{array}{l}\text { This } \\
\text { report }\end{array}$ \\
\hline \#13 & M-4 & a & $\begin{array}{l}\text { epileptic seizures; } \\
\text { low grade tumor }\end{array}$ & c.6709C $>$ T; p.(Arg2237Ter) & NA & {$[24]$} \\
\hline$\# 14$ & M-2 & $\mathrm{a} ; \mathrm{b}$ & none & c. $6756+1 \mathrm{G}>\mathrm{T}$ & de novo & {$[25]$} \\
\hline$\# 15$ & F-33 & $\mathrm{a} ; \mathrm{b} ; \mathrm{e} ; \mathrm{g}$ & none & c.7096_7101del; p.(Asn2366_Phe2367del) & de novo & {$[26]$} \\
\hline \#16 & F-13 & $a ; b ; e$ & none & c. $7395-2 \mathrm{~A}>\mathrm{G}$ & $\begin{array}{l}\text { maternally } \\
\text { inherited } \\
\end{array}$ & {$[27]$} \\
\hline$\# 17$ & M-7 & $\mathrm{a} ; \mathrm{d}$ & none & Entire gene deletion & de novo & {$[28]$} \\
\hline
\end{tabular}

NA: not available.

National Institutes of Health criteria: a) Six or more café-au-lait spots over $5 \mathrm{~mm}$ in greatest diameter in prepubertal individuals and over $15 \mathrm{~mm}$ in postpubertal individuals. b) Two or more neurofibromas of any type or one or more plexiform neurofibromas. c) Freckling in the axillary or inguinal regions. d) Optic glioma. e) Two or more Lisch nodules. f) A distinctive osseous lesions such as sphenoid dysplasia or thinning of long bone cortex with or without pseudarthrosis. g) A first-degree relative with NF-1. 


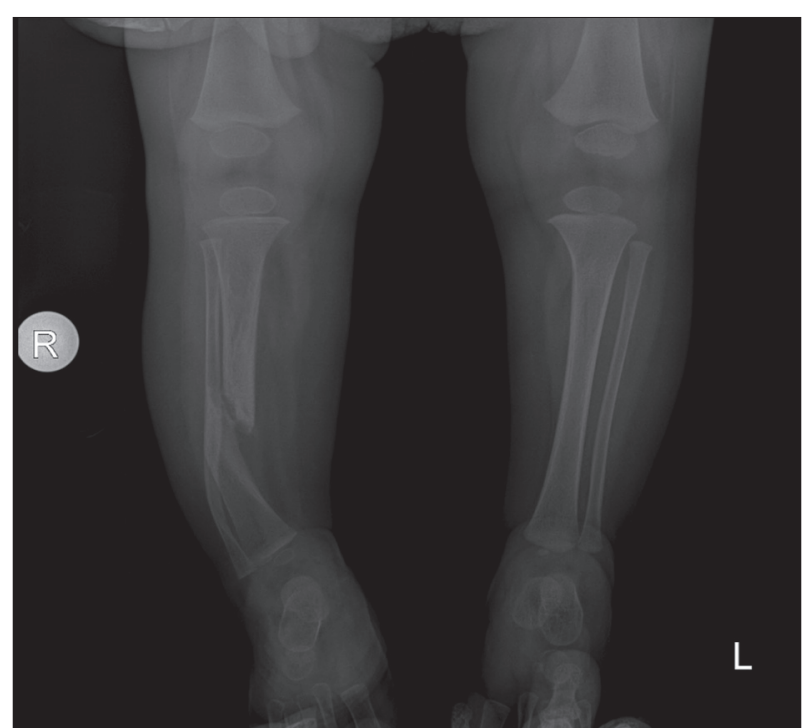

Figure 1. Broken right tibia of patient \#8.

criteria (Table 2), whereas in the mutation-positive patient group, 13 out of 17 patients met these criteria.

We performed physical examinations on the parents of 10 out of 24 patients (patients \#1, \#5, \#6, \#8, \#10, \#15, $\# 16, \# 17, \# 20, \# 22$ ). Five out of 10 of these index cases had at least one clinically affected parent (patients \#1, \#5, $\# 6$, \#8, \#16), whereas the parents of the remaining five cases were found to be normal after a detailed clinical examination (\#15, \#16, \#17, \#20, \#22).

Familial genetic analysis was available for six out of 17 pathogenic variation-positive patients. Three out of
Table 2. Clinical and demographic informations of the index patients that we did not define a pathogenic variant.

\begin{tabular}{|l|l|l|l|}
\hline$\#$ & $\begin{array}{l}\text { Sex- } \\
\text { Age }\end{array}$ & $\begin{array}{l}\text { NIH } \\
\text { Criteria }\end{array}$ & Additional Findings \\
\hline$\# 18$ & F-19 & a & afebrile convulsion; glial tumor \\
\hline$\# 19$ & M-17 & a; b & none \\
\hline$\# 20$ & M-6 & a; b & none \\
\hline$\# 21$ & F-4 & a & none \\
\hline$\# 22$ & M-2 & a & none \\
\hline$\# 23$ & M-16 & a & $\begin{array}{l}\text { T2 flair hyperintensive signals } \\
\text { in the brain }\end{array}$ \\
\hline$\# 24$ & M-15 & c & dysmorphic appearance of the face \\
\hline
\end{tabular}

National Institutes of Health criteria: a) Six or more café-au-lait spots over $5 \mathrm{~mm}$ in greatest diameter in prepubertal individuals and over $15 \mathrm{~mm}$ in postpubertal individuals. b) Two or more neurofibromas of any type or one or more plexiform neurofibromas. c) Freckling in the axillary or inguinal regions. d) Optic glioma. e) Two or more Lisch nodules. f) A distinctive osseous lesions such as sphenoid dysplasia or thinning of long bone cortex with or without pseudarthrosis. g) A first-degree relative with NF-1.

six $(50.0 \%)$ of these pathogenic variations (c. $6756+1 \mathrm{G}>\mathrm{T}$, c.7096_7101del and the entire gene deletion) were de novo compatible with parents who did not have clinical findings of NF1. Patient \#15, who has a c.7096_7101del [p.(Asn2366_Phe2367del)] pathogenic variation, was shown to carry this variation de novo but she has transmitted this pathogenic variation to her son who has clinical findings of NF1 (Table 3). The c.6756+1G $>$ T variation has been found in a patient with a plexiform neurofibroma and cafe-au-lait spots. Parents have been found to be apparently normal after detailed physical examination compatible

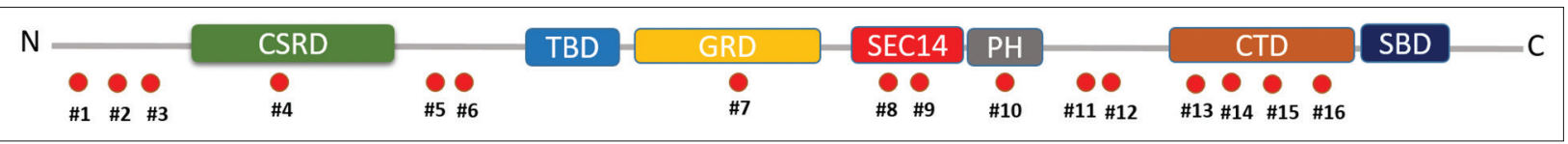

Figure 2. Distribution of mutations (black points) of patients (\#) through the domains of neurofibromin. CSRD: cysteine-serine rich domain; TBD: tubulin binding domain; GRD: GAP-related domain; CTD: C-terminal domain; SBD: syndecan binding domain (domain structure is adapted from Ratner and Miller [7]).

Table 3. Findings of familial patients.

\begin{tabular}{|c|c|c|c|c|}
\hline$\#$ & Sex-Age & NIH Criteria & Additional Findings & Pathogenic Variant (NM_000267) \\
\hline $\begin{array}{l}\text { \#6 } \\
\text { mother of \#6 }\end{array}$ & $\begin{array}{l}\text { F-8 } \\
\text { F-38 } \\
\end{array}$ & $\begin{array}{l}\mathrm{a} ; \mathrm{c} ; \mathrm{g} \\
\mathrm{a} ; \mathrm{c} ; \mathrm{g} \\
\end{array}$ & $\begin{array}{l}\text { none } \\
\text { none }\end{array}$ & c.3230_3230delIT; p.(Ser1078Hisfs*3) \\
\hline $\begin{array}{l}\# 8 \\
\text { father of } \# 8\end{array}$ & $\begin{array}{l}\text { F-7 mths } \\
\text { M-33 }\end{array}$ & $\begin{array}{l}a ; b ; f ; g \\
a ; b ; g\end{array}$ & $\begin{array}{l}\text { none } \\
\text { none }\end{array}$ & c.4802delT; p.(Leu1601Cysfs*2) \\
\hline $\begin{array}{l}\# 12 \\
\text { father of \#12 }\end{array}$ & $\begin{array}{l}\mathrm{F}-2 \\
\mathrm{M}-35 \\
\end{array}$ & $\begin{array}{l}\mathrm{a} \\
\mathrm{a}\end{array}$ & $\begin{array}{l}\text { afebrile convulsion } \\
\text { none }\end{array}$ & c.5630T>A; p.(Leu1877*) \\
\hline $\begin{array}{l}\# 15 \\
\text { son of \#15 }\end{array}$ & $\begin{array}{l}\mathrm{F}-33 \\
\mathrm{M}-7\end{array}$ & $\begin{array}{l}\text { a; b; d;g } \\
\text { a;g }\end{array}$ & $\begin{array}{l}\text { ptosis in his left eye } \\
\text { none }\end{array}$ & c.7096_7101del; p.(Asn2366_Phe2367del) \\
\hline $\begin{array}{l}\# 16 \\
\text { mother of \#16 }\end{array}$ & $\begin{array}{l}\mathrm{F}-13 \\
\mathrm{~F}-40\end{array}$ & $\begin{array}{l}\mathrm{a} ; \mathrm{b} ; \mathrm{d} ; \mathrm{g} \\
\mathrm{a} ; \mathrm{b} ; \mathrm{c} ; \mathrm{d} ; \mathrm{g}\end{array}$ & $\begin{array}{l}\text { none } \\
\text { glial tumor and medial malleolar breakage }\end{array}$ & c. $7395-2 \mathrm{~A}>\mathrm{G}$ \\
\hline
\end{tabular}

National Institutes of Health criteria: a) Six or more café-au-lait spots over $5 \mathrm{~mm}$ in greatest diameter in prepubertal individuals and over $15 \mathrm{~mm}$ in postpubertal individuals. b) Two or more neurofibromas of any type or one or more plexiform neurofibromas. c) Freckling in the axillary or inguinal regions. d) Optic glioma. e) Two or more Lisch nodules. f) A distinctive osseous lesions such as sphenoid dysplasia or thinning of long bone cortex with or without pseudarthrosis. g) A first-degree relative with NF-1. 
with de novo mutation result in the patient. The entire gene deletion was determined in patient \#17 and was shown to be a de novo pathogenic variation by segregation analysis in the parents by MLPA (Table 3).

\section{DISCUSSION}

A lot of different pathogenic variations have been reported in the NF1 gene [18-28] but this is the first report to include results of NGS and MLPA methods for diagnosis of NF1 in Turkish patients. We defined NF1 gene pathogenic variants in 13 out of $17(76.0 \%)$ patients, who met the NIH diagnostic criteria. In a study performed in the Japanese population including 86 NF1 patients [11], the mutation detection rate of the NGS method has been reported to be $92.1 \%$. In another study performed on 279 NF1 patients, researchers suggested the mutation detection rate of NGS was $88.0 \%$ (3). The different mutation frequencies in the studies may be because of the differences between the library preparation method and specifications of the studied patient group. In our study, eight out of 24 patients $(33.33 \%)$ had isolated cafe-aulait spots, which may also be a manifestation of other ras pathway disorders.

We did not define a pathogenic variation in four out of 17 patients who met the NIH diagnostic criteria. We used an amplicon-based capture for resequencing the coding regions and exon/intron boundaries (splice sites) of the NF1 gene. Deep intronic pathogenic variations were also reported in the patients with NF1 patients [18]. We propose that it is possible to miss some pathogenic variations located in deep intronic regions with capturing exonic and known splice sites instead of the whole gene.

We report here two different truncating mutations in two unrelated patients with pseudoarthrosis. Being a relatively rare manifestation of NF1 disease, breakage because of sphenoid dysplasia is one of the most serious clinical finding restricting the life quality of children with NF1.

Pathogenic variants found in this study were different for each family although there are a number of studies reporting some recurrent mutation hotspots for the NF1 gene [29,30]. Terzi et al. [31] suggested screening the entire coding exons of the NF1 gene for genetic analysis as a result of their study reporting a novel and two known NF1 gene mutations in a cohort of 100 Turkish NF1 patients using a targeted resequencing method for screening recurrent mutation hotspots. They concluded that each population may have different mutation distribution patterns in the NF1 gene. Despite the differences of the sample sizes between these two studies in the Turkish population, both support the need for a comprehensive approach for the genetic analysis of NF1 patients. Some of the pathogenic variations defined in this study were in the C-terminal region, which has recently been reported to have an important role in the cellular process [32].

There was no obvious genotype-phenotype correlation in this study but small number of studied patients might be one of the reasons. Another additional factor is the age dependence of some manifestations of the disease so it is difficult to compare family members unless they are at the same age. Highly variable expressivity has been reported in a lot of studies for NF1. Genotypephenotype correlation has been reported for a few of the mutations. A well-known example is the absence of cutaneous neurofibromas in the patients with a $3 \mathrm{bp}$ inframe deletion in the NF1 gene (c.2970-2972delAAT) [33], and a more severe phenotype including intellectual disability in the patients who have a NF1 microdeletion syndrome [34].

The majority of the pathogenic variations of NF1 reported in the literature are caused by a premature stop codon generation (9). Three novel pathogenic variants (3/17) defined in this study were predicted to cause premature stop codon generation either due to frameshift deletions [c.3230_3230delT, p.(Ser1078Hisfs*3); c.4802delT, p.(Leu1601Cysfs*2)] or single nucletoide [c.5630T $>$ A, p.(Leu1877*)] variations.

The NF1 mutations cause a predisposition to cancer as do other ras pathway disorders [35]. Considering the age-dependent nature of some manifestations, it would be useful to define pathogenic variations in families with NF1 for a closer follow-up. We performed segregation analysis by Sanger sequencing in this study but, although it is impossible to define germline mosaicism by performing NGS in the blood samples of parents, NGS would reveal the somatic mosaic pathogenic variations in apparently normal patients.

In conclusion, we suggest that NGS and MLPA methods are practical and helpful tools for genetic diagnosis of NF1. The definition of three novel and 13 known pathogenic variants and a large gene deletion, using a combined approach including NGS and MLPA, supports the effectiveness of new technologies for rapid and accurate genetic diagnosis of NF1 in our population.

Declaration of Interest. The authors report no conflicts of interest. The authors alone are responsible for the content and writing of this article. 


\section{REFERENCES}

1. Friedman JM. Neurofibromatosis 1. In: Pagon RA, Adam MP, Ardinger HH, Wallace SE, Amemiya A, Bean LJH, et al., Editors. Gene Reviews ${ }^{\circledR}$ [Internet]. Seattle, WA, USA: University of Washington, 1993-2016.

2. Brosius S. A history of von Recklinghausen's NF1. J Hist Neurosci. 2010; 19(4): 333-348.

3. Pasmant E, Parfait B, Luscan A, Goussard P, BriandSuleau A, Laurendeau I, et al. Neurofibromatosis type 1 molecular diagnosis: What can NGS do for you when you have a large gene with loss of function mutations? Eur J Hum Genet. 2015; 23(5): 596-601.

4. Gutmann DH, Aylsworth A, Carey JC, Korf B, Marks $\mathrm{J}$, Pyeritz RE, et al. The diagnostic evaluation and multidisciplinary management of neurofibromatosis 1 and neurofibromatosis 2. JAMA. 1997; 278(1): 51-57.

5. Cung W, Freedman LA, Khan NE, Romberg E, Gardner PJ, Bassim CW, et al. Cephalometry in adults and children with neurofibromatosis type 1: Implications for the pathogenesis of sphenoid wing dysplasia and the "NF1 facies." Eur J Med Genet. 2015; 58(11): 584-590.

6. Sant DW, Margraf RL, Stevenson DA, Grossmann AH, Viskochil DH, Hanson H, et al. Evaluation of somatic mutations in tibial pseudarthrosis samples in neurofibromatosis type 1. J Med Genet. 2015; 52(4): 256-261.

7. Ratner N, Miller SJ.ARASopathy gene commonly mutated in cancer: The neurofibromatosis type 1 tumour suppressor. Nat Rev Cancer. 2015; 15(5): 290-301.

8. Bernier A, Larbrisseau A, Perreault S. Café-au-lait macules and neurofibromatosis type I: A review of the literature. Pediatr Neurol. 2016; 60: 24-29.

9. Stenson PD, Mort M, Ball EV, Shaw K, Phillips A, Cooper DN. The Human Gene Mutation Database: Building a comprehensive mutation repository for clinical and molecular genetics, diagnostic testing and personalized genomic medicine. Hum Genet. 2014; 133(1): 1-9.

10. Maruoka R, Takenouchi T, Torii C, Shimizu A, Misu $\mathrm{K}$, Higasa $\mathrm{K}$, et al. The use of next-generation sequencing in molecular diagnosis of neurofibromatosis type 1: A validation study. Genet Test Mol Biomarkers. $2014 ; 18(11)$ : 722-735.

11. Zhu L, Zhang Y, Tong H, Shao M, Gu Y, Du X, et al. Clinical and molecular characterization of NF1 patients: Single-center experience of 32 patients from China. Medicine (Baltimore). 2016; 95(10): e3043.
12. van Minkelen $\mathrm{R}$, van Bever $\mathrm{Y}$, Kromosoeto JN, Withagen-Hermans CJ, Nieuwlaat A, Halley DJ, et al. A clinical and genetic overview of 18 years neurofibromatosis type 1 molecular diagnostics in The Netherlands. Clin Genet. 2014; 85(4): 318-327.

13. Bianchessi D, Morosini S, Saletti V, Ibba MC, Natacci $\mathrm{F}$, Esposito S, et al. 126 novel mutations in Italian patients with neurofibromatosis type 1 . Mol Genet Genomic Med. 2015; 3(6): 513-525.

14. Terzi YK, Oguzkan-Balci S, Anlar B, Aysun S, Guran S, Ayter S. Reproductive decisions after prenatal diagnosis in neurofibromatosis type 1: Importance of genetic counseling. Genet Couns. 2009; 20(2): 195-202.

15. Robinson JT, Thorvaldsdóttir H, Winckler W, Guttman M, Lander ES, Getz G, et al. Integrative genomics viewer. Nat Biotechnol. 2011; 29(1): 24-26.

16. Wildeman M, van Ophuizen E, den Dunnen JT, Taschner PE. Improving sequence variant descriptions in mutation databases and literature using the mutalyzer sequence variation nomenclature checker. Hum $\mathrm{Mu}-$ tat. 2008; 29(1): 6-13.

17. Richards S, Aziz N, Bale S, Bick D, Das S, GastierFoster J, et al. ACMG Laboratory Quality Assurance Committee. Standards and guidelines for the interpretation of sequence variants: A joint consensus recommendation of the American College of Medical Genetics and Genomics and the Association for Molecular Pathology. Genet Med. 2015; 17(5): 405-424.

18. Griffiths S, Thompson P, Frayling I, Upadhyaya M. Molecular diagnosis of neurofibromatosis type 1:2 years experience. Fam Cancer. 2007; 6(1): 21-34.

19. Leskelä HV, Kuorilehto T, Risteli J, Koivunen J, Nissinen M, Peltonen S, et al. Congenital pseudarthrosis of neurofibromatosis type 1: Impaired osteoblast differentiation and function and altered NF1 gene expression. Bone. 2009; 44(2): 243-250.

20. Robinson PN, Buske A, Neumann R, Tinschert S, Nürnberg P. Recurrent 2-bp deletion in exon 10c of the NF1 gene in two cases of von Recklinghausen neurofibromatosis. Hum Mutat. 1996; 7(1): 85-88.

21. Maynard J, Krawczak M, Upadhyaya M. Characterization and significance of nine novel mutations in exon 16 of the neurofibromatosis type 1 (NF1) gene. Hum Genet. 1997; 99(5): 674-676.

22. Upadhyaya M, Maynard J, Osborn M, Harper PS. Six novel mutations in the neurofibromatosis type 1 (NF1) gene. Hum Mutat. 1997; 10(3): 248-250. 
23. Cawthon RM, Weiss R, Xu GF, Viskochil D, Culver M, Stevens J, et al. A major segment of the neurofi-bromatosis type 1 gene: cDNA sequence, genomic structure, and point mutations. Cell. 1990; 62(1): 193-201.

24. Fahsold R, Hoffmeyer S, Mischung C, Gille C, Ehlers $\mathrm{C}$, Kücükceylan $\mathrm{N}$, et al. Minor lesion mutational spectrum of the entire NF1 gene does not explain its high mutability but points to a functional domain upstream of the GAP-related domain. Am J Hum Genet. 2000; 66(3): 790-818.

25. De Luca A, Schirinzi A, Buccino A, Bottillo I, Sinibaldi L, Torrente I, et al. Novel and recurrent mutations in the NF1 gene in Italian patients with neurofibromatosis type 1. Hum Mutat. 2004; 23(6): 629-643.

26. Abernathy CR, Colman SD, Kousseff BG, Wallace MR. Two NF1 mutations: Frameshift in the GAPrelated domain, and loss of two codons toward the 3 ' end of the gene. Hum Mutat. 1994; 3(4): 347-352.

27. Brems H, Park C, Maertens O, Pemov A, Messiaen $\mathrm{L}$, Upadhyaya $\mathrm{M}$, et al. Glomus tumors in neurofibromatosis type 1: Genetic, functional, and clinical evidence of a novel association. Cancer Res. 2009; 69(18): 7393-7401.

28. Valero MC, Martín Y, Hernández-Imaz E, Marina Hernández A, Meleán G, Valero AM, et al. A highly sensitive genetic protocol to detect NF1 mutations. J Mol Diagn. 2011; 13(2): 113-122.

29. Böddrich A, Robinson PN, Schülke M, Buske A, Tinschert S, Nürnberg P. New evidence for a mutation hotspot in exon 37 of the NF1 gene. Hum Mutat. 1997; 9(4): 374-377.
30. Ars E, Kruyer H, Morell M, Pros E, Serra E, Ravella A, et al. Recurrent mutations in the NF1 gene are common among neurofibromatosis type 1 patients. J Med Genet. 2003; 40(6): e82.

31. Terzi YK, Oguzkan S, Anlar B, Aysun S, Ayter S. Neurofibromatosis: Novel and recurrent mutations in Turkish patients. Pediatr Neurol. 2007; 37(6): 421-425.

32. Koliou X, Fedonidis C, Kalpachidou T, Mangoura D. Nuclear import mechanism of neurofibromin for localization of the spindle and function in chromosome con-gression. J Neurochem. 2016; 136(1): 78-91.

33. Upadhyaya M, Huson SM, Davies M, Thomas N, Chuzhanova N, Giovannini S, et al. An absence of cutaneous neurofibromas associated with a 3-bp inframe deletion in exon 17 of the NF1 gene (c.2970-2972 delAAT): Evidence of a clinically significant NF1 genotype-phenotype correlation. Am J Hum Genet. 2007; 80(1): 140-151.

34. Pasmant E, Sabbagh A, Spurlock G, Laurendeau I, Grillo E, Hamel MJ, et al. NF1 microdeletions in neurofi-bromatosis type 1: From genotype to phenotype. Hum Mutat. 2010; 31(6): E1506-E1518.

35. Rad E, Tee AR. Neurofribromatosis type I: Fundamental insights into cell signalling and cancer. Semin Cell Dev Biol. 2016; 52: 39-46. 
